\title{
The RMS US inland flood model
}

\author{
Sonja Jankowfsky ${ }^{1,2, a}$, Arno Hilberts ${ }^{2}$, Christian Mortgat $^{1}$, Shuangcai Li ${ }^{1}, \mathrm{Na} \mathrm{Xu}^{1}, \mathrm{Yi} \mathrm{Mei}^{1}$, Stephan Tillmanns ${ }^{3}, \mathrm{Ye} \mathrm{Tian}^{1}$, \\ Yang Yang ${ }^{1}$ \\ ${ }^{1}$ Risk Management Solutions, Inc., 7575 Gateway Boulevard, Newark, CA 95355, USA \\ ${ }^{2}$ Risk Management Solutions, Inc., Peninsular House, 30 Monument Street, London EC3R 8NB, UK \\ ${ }^{3}$ Risk Management Solutions, Inc., Stampfenbachstrasse 85, 8006 Zuerich, Switzerland
}

\begin{abstract}
The RMS US inland flood model provides flood hazard data of up to 10x10m resolution for the Contiguous United States for different return periods. The flood maps were developed using a series of physically based models. First, several thousand years of precipitation were simulated using principal component analysis coupled to a tropical cyclone precipitation model. Then, discharge and runoff were calculated using a semi-distributed rainfall runoff and routing model based on the TOPMODEL approach run at an hourly time step. This in turn forms the input to the fluvial and pluvial inundation models, which uses the shallow water equation to simulate flood propagation. Each of the individual model components such as precipitation, discharge and flood extent and depth were validated individually. The model generally performed very well compared to available flood maps, especially in the high exposure areas, even if it has some difficulties in the dry low exposure areas of the United States, which are heavily influenced by water management. The flood maps will be the base for the fully probabilistic loss model including a financial model. Via the simulated Hurricane track data set the flood model will be coupled to the RMS North Atlantic Hurricane model.
\end{abstract}

\section{Introduction}

Catastrophe risk models are widely used in the insurance industry to estimate the financial consequences of catastrophes. They provide a tool to estimate the exceedance probability of loss for a given location, which helps the insurance industry to derive their pricing models. Catastrophe risk models usually consist of hazard models that are linked to vulnerability, exposure and financial loss models. Here, we want to present the hazard part of the RMS flood risk model for the Contiguous United States (USFL model). The article first presents the model methodology and details the input data and physics behind each part, after which we present the model domain and setup and show some of the results for the individual model components.

\section{Methodology}

The flood hazard model developed for USFL shares a significant part of its setup and structure with other RMS flood models $[1,2]$. Figure 1 gives an overview of the different model components, which will be presented separately in the following sections.

\footnotetext{
${ }^{\mathrm{a}}$ Corresponding author: sonja.jankowfsky@rms.com
}

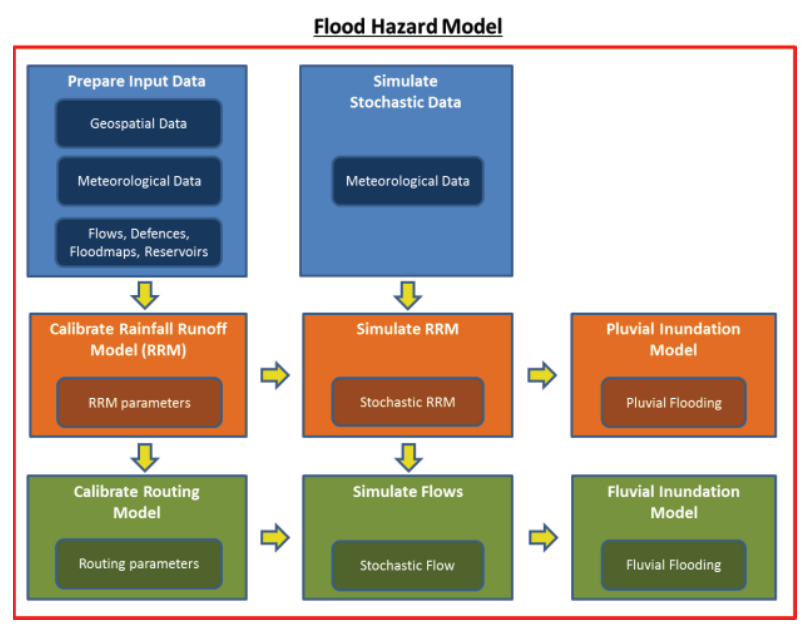

Figure 1. RMS flood hazard model.

\subsection{Input data}

The model needs different meteorological and geospatial input data, as well as discharge information. For most of the input data different sources were compared. In the following paragraph we will only name the final selection of input data. For the precipitation and climatic forcing data (such as temperature, wind components, surface pressure, specific humidity and 
longwave and shortwave radiation) the North Atlantic Land Data Assimilation System II (NLDAS II) available for the period from 1979 to present with an hourly time step was selected for the Rainfall Runoff Model (RRM) and Routing calibration. In addition, for the simulation of precipitation we used the CPC daily precipitation data which are available from 1948 on and the NOAA HURDAT data set. The daily discharge of around 4500 USGS gauges, which had data for the 1979-2013 time period, as well as around 11000 peak USGS gauges having at least 20 years of data and the rating curves of around 2000 USGS gauges were used for model validation. The Digital elevation model is one of the most important input data of flood hazard modelling. Here, we used version 2 of the National Hydrologic Dataset at $30 \times 30 \mathrm{~m}$ resolution for the RRM and Routing model and the National Elevation Data Set at $10 / 30 \mathrm{~m}$ resolution for the inundation modelling. In the 200 largest cities, the river network was manually corrected to fit with Google Earth. Around 1000 reservoirs from the Global Reservoir and Dam (GRanD) database (Global Water System project, Bonn, Germany) were explicitly modelled. The National Land Cover Data base at $30 \mathrm{~m}$ resolution and Topographically Integrated Geographic Encoding and Referencing (TIGER) data provided land use information. FEMA hazard maps from 2013 were used for the validation of the $100 / 500$ year flood zones.

\subsection{Simulation of stochastic data}

As existing data records in the US barely cover 100 years, it is necessary to simulate a stochastic data set in order to estimate the hazard for higher return periods. In the flood model, the stochastic data are the forcing variables, which are the precipitation, temperature, wind components, surface pressure, shortwave and longwave radiation and the specific humidity. The precipitation in the US can be divided in two main components which have very different properties: Non-tropical cyclone (non-TC) precipitation and tropical cyclone (TC) precipitation. Here, the two components were simulated separately. The non-TC precipitation was generated using principal component analysis [3], whereas the hurricane driven precipitation was simulated with the RMS TC rain model [4] based on the RMS North Atlantic Hurricane event set. The TC precipitation was then merged with the non-TC precipitation to generate a set of 50000 years of precipitation. The remaining forcing data were generated using an analogous mapping method.

\subsection{Rainfall-runoff and Routing model}

\subsubsection{Calibration}

Runoff generation and flow routing were simulated separately using a rainfall-runoff (RRM) and a routing model. The RRM is a semi-distributed model based on the TOPMODEL approach [5]. The catchment was divided in classes of homogenous wetness index, which represent the combined effect of terrain slope and accumulation area. The vertical water fluxes were calculated dynamically between three zones (root, unsaturated and saturated zones) using a massconservative scheme. The evapotranspiration affecting the root zone, was calculated using the Penman-Monteith equation based on the atmospheric forcings. Precipitation can be stored as snow in different elevation bands and the snow melt was calculated for each time step based on the temperature and radiation terms [6]. The routing model is based on the Muskingum-Cunge approach [7, 8] and includes the simulation of lakes and reservoirs using the linear reservoir approach.

The rainfall-runoff and routing models were calibrated separately using the multi-objective evolutionary Non-dominated Sorting Genetic Algorithm II [9] to optimize the root mean square error (RMSE), the bias and the RMSE for high flow periods.

\subsubsection{Simulation}

Once the model was calibrated, the parameters were distributed to the remaining ungauged catchments based on distance and catchment characteristics. The calibrated RRM and routing models were then run with the stochastic precipitation and forcing data as input. This allowed us to create time series of 50,000 years of hourly discharge and surface runoff which we used to drive the inundation model resulting in flood maps for various return periods.

\subsection{Inundation Model}

The inundation model consists of a combination of pluvial and fluvial inundation models. The fluvial inundation model simulates the flooding caused by the major river network, whereas the pluvial model simulates the off-flood plain inundation of minor streams and local ponding. Both models solve the $2 \mathrm{D}$ shallow water equations numerically using the finite volume method and a Riemann-Solver. In order to allow the calculation of the inundation at the large scale of the US, but with a relatively fine resolution (10-30m grids), the code was setup to run in parallel on a cluster of GPUs. Whereas the fluvial model takes the simulated discharges as an input, the pluvial model was forced by dynamically simulated surface runoff. This approach allows to have two numerically stable models which can be run in a reasonable time on several thousand catchments for all required return periods.

\section{Model application to the United States}

The US flood model covers the Contiguous US, (i.e., the continental United States, excluding Alaska). From East to West the climate and hydrology changes considerably. The Eastern United States have a wetter climate and can receive very heavy precipitation from Hurricanes, whereas the mid-west is very dry and receives only seasonal precipitation. Snowmelt plays an 
important role in nearly all states except the coastal areas. Due to the unequal distribution of water especially in the dry Western United States, surface runoff and river flow are heavily influenced by water management.

The model domain was subdivided in 16 river basins and 15,514 catchments with an average size of $500 \mathrm{~km}^{2}$ (Figure 2). 600,000 km of river network were modelled with the fluvial inundation model.

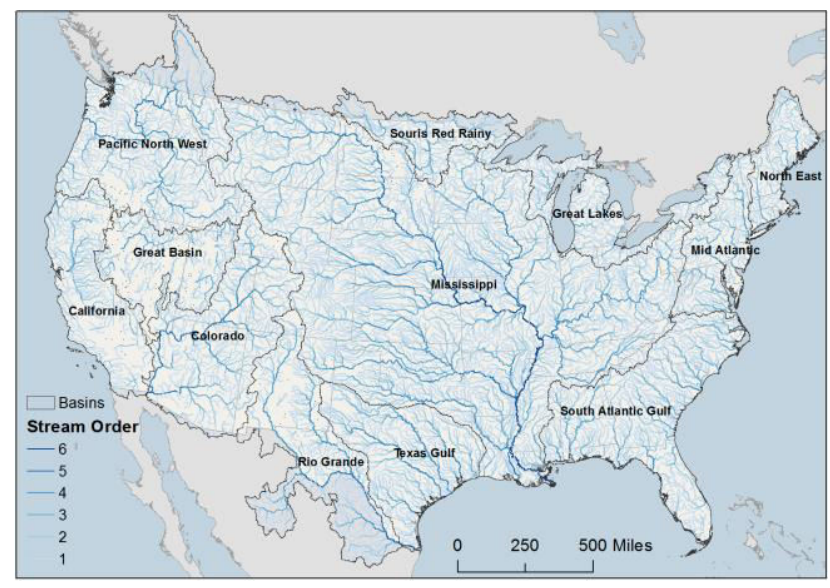

Figure 2. RMS US flood model extent with river basins and fluvial river network.

In order to assure a realistic simulation of the flood risk, the individual model components were validated, as well as the final flood maps. The following sections show some results and validations for the simulation of the precipitation, the calibration of the RRM and Routing model and the flood maps.

\subsection{Simulated stochastic precipitation}

Many different validations were performed on the simulated precipitation. First, TC and non-TC precipitation were validated individually. For example, the output from the TC rainfall model was compared to the observed CPC average annual rainfall and selected Hurricane footprints (such as Dolly in 2008, see Figure 3) were simulated and compared to observed values. Monthly and daily means of the simulated PCA output were compared to observed means and seasonality as well as spatial correlations were checked.
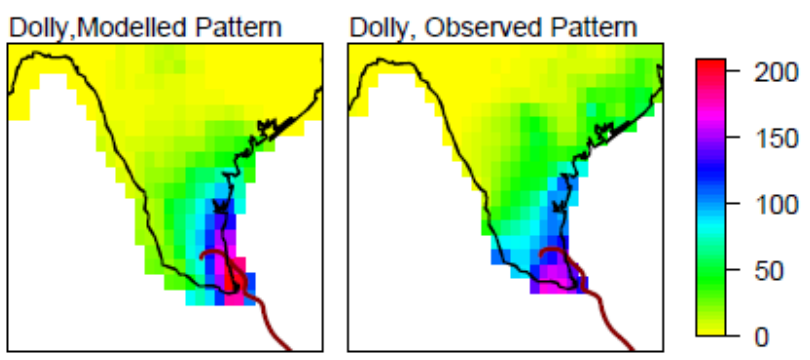

Figure 3. Modelled (left) and observed (right) rain in $\mathrm{mm}$ for the TC Dolly in 2008.
Figure 4 shows the comparison of the maximum daily rainfall of the combined precipitation for a return period of 50 years. The modelled precipitation simulates very well the general trend with higher precipitation in the Hurricane-influenced states and the West coast and low precipitation in the mid-west.
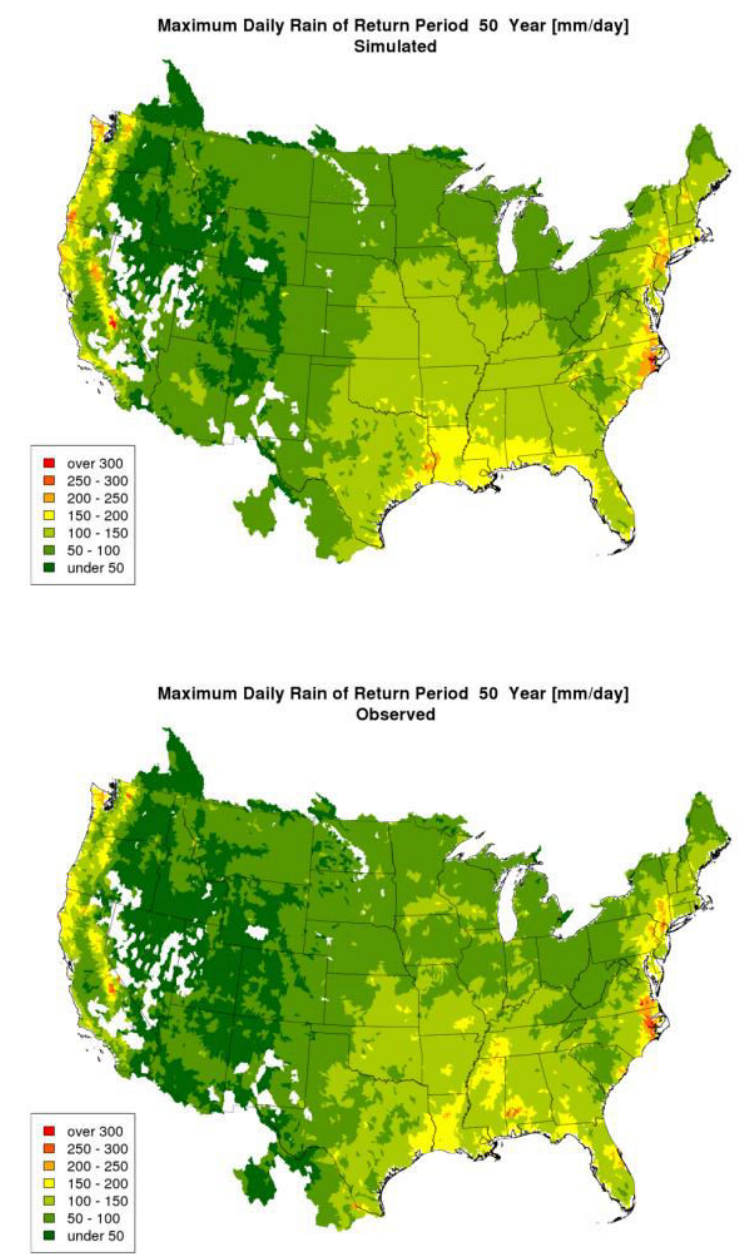

Figure 4. Simulated (top) and observed (bottom) maximum daily rain for return period 50 year $(\mathrm{mm} /$ day).

\subsection{Calibration of Rainfall-Runoff and Routing model and simulation of stochastic discharge}

The RRM was originally calibrated to daily discharge at approx. 4500 gauge stations leading to one parameter set per gauge. After quality control and redistribution of parameters, part of the gauges had to be discarded in order to have a set of parameters leading to good performance upstream and downstream. The RRM parameters were then fixed and the routing parameters calibrated. The model performance in all high exposure areas was checked individually and the model recalibrated if necessary. Around 2850 gauges were used for the final parameter set and results $\left(\mathrm{r}^{2}\right)$ are shown in Figure 5. In general, as expected, the model performs better for larger upstream areas as local processes are 
averaged out. Furthermore, results were better in wet areas with high runoff coefficients, as the dry areas in the mid-west of the US are heavily influenced by water management, or by water disippation into karstic sinks. In some areas, such as the Sacramento area, CA, the modelled discharge was adapted based on regressions in order to account for the impact of flood bypasses.

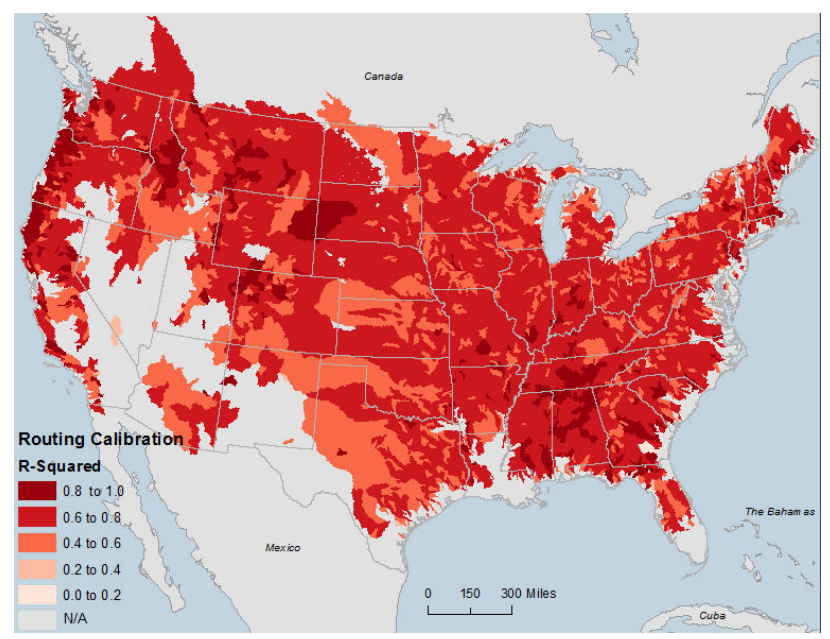

Figure 5. $\mathrm{R}^{2}$ for the routing calibration.

The ungauged areas obtained their parameters using a nearest-neigbour approach where hydrological and hydraulic similarity was incorporated as well. The final RRM and Routing parameter sets were used to create the stochastic runoff and discharge time series. The quality of the stochastic simulation was checked by comparing runoff coefficients, discharge for different return periods and the spatial correlation for key locations. In Figure 6 we show the spatial correlation of simulated versus observed monthly discharge. We can see e.g. that Portland is heavily correlated to the cities on the west coast, but not to the cities on the east cost. Furthermore, the simulated discharge statistics were compared to the estimates based on fitting an extreme value distribution to discharge for approx. 11,000 USGS gauges for which a sufficiently long record of peak discharge data was available.

\begin{tabular}{|c|c|c|c|c|c|c|c|c|c|c|c|}
\hline \\
\hline \multicolumn{12}{|l|}{$\begin{array}{l}\text { San Diego } \\
\text { San Jose }\end{array}$} \\
\hline Detroit & 0.0 & 0.0 & 1.0 & & & & & & & & \\
\hline New York & 0.3 & 0.2 & 0.1 & 1.0 & & & & & & & \\
\hline Philadelphia & 0.2 & 0.2 & 0.1 & 0.8 & 1. & & & & & & \\
\hline Seattle & 0.4 & 0.6 & 0.0 & 0.3 & 0.2 & 1. & & & & & \\
\hline Portland & 0.5 & 0.7 & 0.0 & 0.3 & 0.2 & 0.8 & 1. & & & & \\
\hline Orlando & -0.1 & -0.2 & -0.1 & 0.0 & 0.1 & -0.2 & -0.1 & 1. & & & \\
\hline Atlanta & 0.3 & 0.3 & 0.1 & 0.3 & 0.2 & 0.3 & 0.3 & 0.1 & 1. & & \\
\hline Dallas & 0.1 & 0.1 & 0.1 & 0.0 & 0.0 & 0.1 & 0.1 & -0.1 & 0.2 & & \\
\hline San Antonio & -0.1 & -0.1 & 0.0 & -0.1 & -0.1 & -0.1 & -0.1 & 0.1 & 0.1 & 0.4 & 1. \\
\hline & 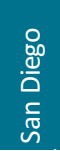 & $\begin{array}{l}\stackrel{0}{u} \\
\stackrel{0}{c} \\
\substack{c \\
N}\end{array}$ & $\begin{array}{l}\text { 흘 } \\
\text { 휴 } \\
\text { 口. }\end{array}$ & $\begin{array}{l}\text { ㄴ } \\
\frac{1}{0} \\
3 \\
0 \\
z\end{array}$ & 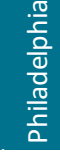 & 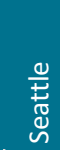 & 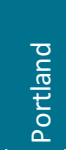 & $\begin{array}{l}\text { 음 } \\
\frac{\mathrm{C}}{\mathrm{N}} \\
\text { ㅇ }\end{array}$ & $\begin{array}{l}\frac{\pi}{\stackrel{5}{L}} \\
\frac{\pi}{\pi} \\
\frac{\pi}{4}\end{array}$ & $\frac{\underline{w}}{\overline{\underline{\widetilde{C}}}}$ & 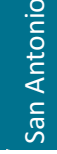 \\
\hline
\end{tabular}

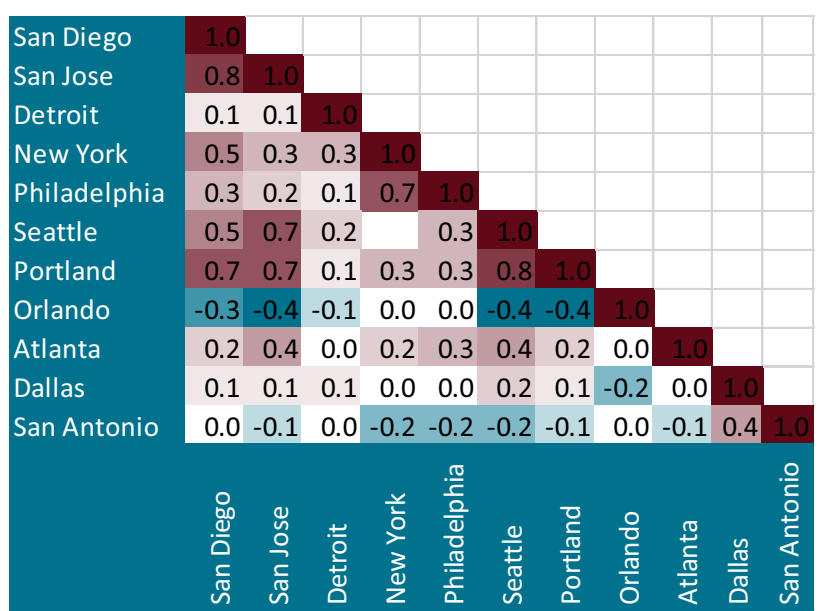

Figure 6. Simulated (top) and observed (bottom) correlation of monthly discharge for key locations in the US.

\subsection{Undefended flood maps}

A large quality analysis exercise on the return period flood maps was then conducted. A systemetic check of the 100 and 500 year return period RMS flood maps to the equivalent FEMA 100 and 500 year zones was conducted. Flood extents were compared, as well as volume captured in the flood zones, average and maximum depth and calculated exposure accumulations wherever FEMA flood depth was available. Furthermore, we compared the flood depth at river gauges to the depth obtained from the rating curves given with the USGS gauges. All the spatial information such as flood maps, gauges, defences, catchments, etc. were uploaded to a geoserver in order to facilitate the quality analysis and comparison to observed events for particular locations. Figure 7 shows an example flood map for Philadelphia and it's comparison to the FEMA map. In general the RMS modelled maps compare well with FEMA, but as RMS models pluvial as well as fluvial inundation, RMS maps cover a larger total area. We performed checks to ensure the continuity of flood maps between model units. All in all, the quality checks that were performed have lead to many iterations of the modelled inundations, and have thus led to significant improvements of the model and flood maps. 


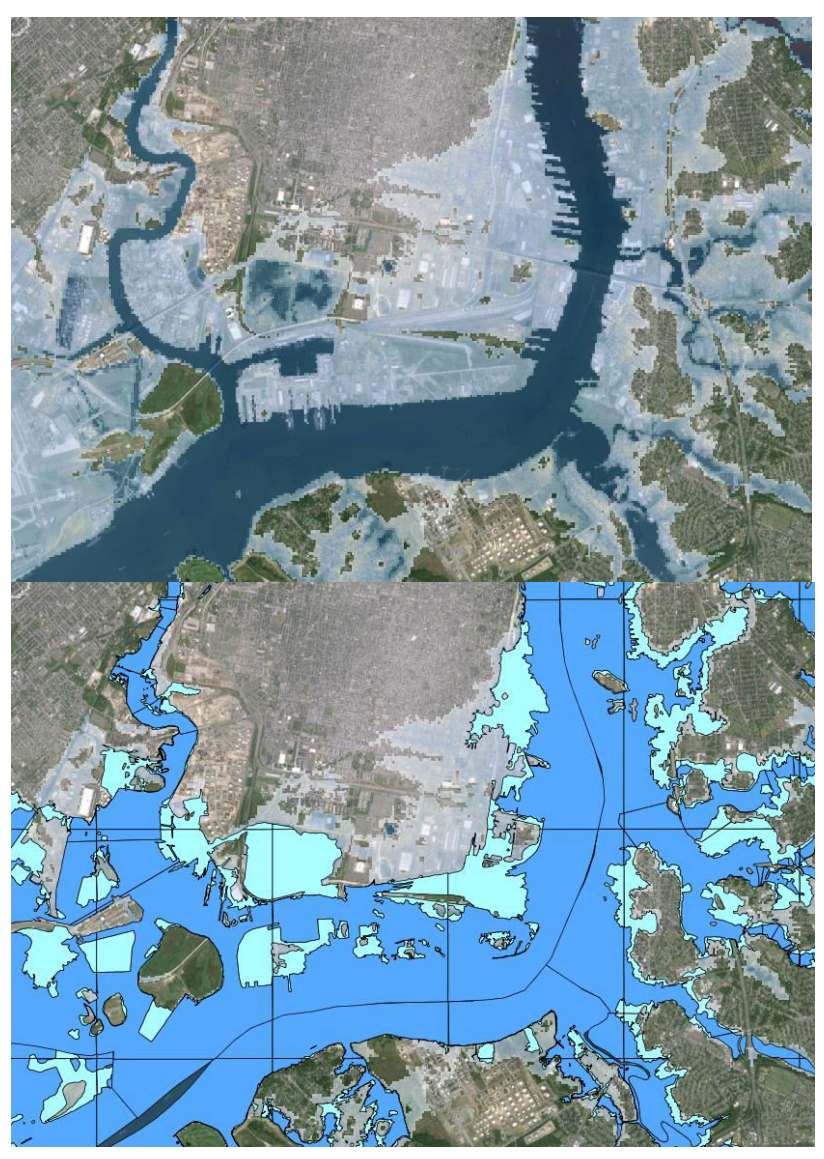

Figure 7. Simulated 100 year return period map in Philadelphia (top) versus FEMA flood zones.

\section{Conclusions}

The RMS US Flood Hazard model assembles a series of physically based simulation models from the simulation of precipitation and climatic forcings, and the simulation of discharge and runoff using a calibrated rainfall-runoff and routing model, to the simulation of flood extent using a $2 \mathrm{D}$ inundation model in order to create flood maps for different return periods. The model covers the Contiguous United States at a resolution of 10$30 \mathrm{~m}$. Each of the individual model components was validated against observed data and the model was manually adjusted and improved where necessary. As the RMS flood model includes pluvial and fluvial flood risk, the flood maps cover the complete model area, "filling gaps" in the governmental FEMA maps: usually the RMS flooded areas extend further upstream than FEMA. Furthermore, as it is a fully stochastic model based on several thousand years of simulated precipitation, more and longer return periods are covered.

In this article, we presented aspects of the development of the hazard model underpinning the undefended flood maps. The undefended flood maps will also be used as the input to the loss model. For this, a defence model will be applied to the flood maps and losses for each location will be calculated based on RMS vulnerability functions and exposure estimates. In doing so, we allow inundation frequency and severity to be translated into loss exceedances. This is used by the insurance industry to better understand and price flood risk. As the RMS North Atlantic Hurricane track set data was used for the development of the stochastic precipitation, the models will eventually be linked allowing for the combination of financial risk from wind, surge and flood.

\section{References}

1. Savina M., Hilberts A., Peiris N., Nicotina L., Rentzos P., Assteerawatt A., Zanardo S., Zovi F. (2016). RMS pan-Europe HD Flood models. Floodrisk conference 2016.

2. Assteerawatt A., Tsaknias D., Azemar F., Gosh S., Hilberts A. (2016). Large-scale and High-resolution Flood Risk Model for Japan. Floodrisk conference 2016.

3. Ehrendorfer, M. 1987. A regionalization of Austria's precipitation climate using principal component analysis, J. Climatol. 7, 71-89.

4. Grieser J. and Jewson S. (2011). The RMS TC Rain Model. Meteorologische Zeitschrift 21(1), 79-88.

5. Beven K. and Kirkby M. (1979). A physically based, variable contributing area model of basin hydrology. Hydroligical Sciences Bulletin 24 (1), 43-69.

6. Pellicciotti F., Brock B., Strasser U., Burlando P., Funk M., Corripio J. (2005). An enhanced temperature-index glacier melt model including the shortwave radiation balance: development and testing for Haut Glacier d'Arolla, Switzerland. Journal of Glaciology 51(175), 573-587.

7. Cunge J.A. (1969). On the subject of a flood propagation computation method (Muskingum method), Journal of. Hydraulic Research, 7(2), 205230.

8. Georgakakos K.P. (1990). A State-Space Model for Hydrologic River Routing. Water Resources Research 26(5), 827-838.

9. Deb K., Pratap A., Agarwal S., Meyarivan T. (2002). A fast and elitist multiobjective genetic algorithm: NSGA-II, IEEE Transactions on evolutionary computation, 6(2), 182-197. 